\title{
Indoor air quality - buildings design
}

\author{
Ingrid Juhásová Šenitková ${ }^{1, *}$ \\ ${ }^{1}$ Institute of Technology and Business in České Budějovice, Department of Civil Engineering, \\ Okružní 517/10, 37001 České Budějovice Czech Republic
}

\begin{abstract}
Growing attention is being paid to indoor air quality as one of the main health and well-being factors. The indoor research is concerned mostly to indoor air chemicals within indoor engineering related to building design. The providing good indoor air quality can be achieved effectively by avoiding or reducing indoor air pollution sources and by selecting low-polluting building materials, both being low-cost and energyefficient solutions. On the base of the last large experimental monitoring results, it was possible to know the level of selected indoor chemicals occurrence, rank them as well as to predict the tendencies of occurrence and establish the priorities for the future. There has been very limited attention to rigorous analysis of buildings actual environmental impacts to date. Healthy/green/sustainable building practices are typically applied in unsystematic and inconsistent ways often without resolution of inherent conflicts between and among such practices. Designers, products manufacturers, constructors, and owners declare their buildings and the applied technologies to be beneficial to the environment without validating those claims.
\end{abstract}

\section{Introduction}

Provided an environmental and economic will within our society will became aware of the real needs of solving the healthy/green/sustainable buildings problem - we are able to offer the models and strategies the tools, and criteria, and finally the construction technology and an architectural idiom to design, to build, and to maintain a sustainable building on short and long term as well as affordable. A health impact assessment and an environment impact assessment are needed to judge the real quality of a building and particularly indoor design.

As we spend most of our life indoors, it is easy to understand that the most important environment in relation to our health is the indoor environment. In the last several years, a growing body of scientific evidence has indicated that the air within buildings can be more seriously polluted than the outdoor air in even the largest and most industrialized cities. Indoor pollution sources that release gases or particles into the air are the primary cause of indoor air quality problems in the buildings [1].

Growing attention is being paid to indoor environment as one of the main health and well-being factors of building users. The main purpose of buildings is to create indoors more suitable for persons and processes than outdoors. However in buildings and shelters it

\footnotetext{
*Corresponding author: 14667@mail.vstecb.cz
} 
is not only the thermal climate that is changed. The climate shell also stops the free air movement. The dilution of pollutants from close to man pollutants sources is diminished. Indoor air quality problems are more common in the buildings with insufficient ventilation. It is evident that there is need to increase the outdoor air supply in the indoor of buildings, to minimize the exposure of indoor pollutants. Furthermore, building materials, building constructions and indoor activities should be selected on the principle that the level of indoor air should be of the best quality or the concentration of negative agents should be as low as reasonably achievable. There are two classical approaches to reach a required level of indoor air quality in terms of pollutants. One is by dilution and other is by source control. Nowadays it seems that dilution is still the more accepted approach. It is the way of obtaining better indoor air quality [2].

This was and is the basis of the need for ventilation and for discussions on indoor air quality. Consequently, the main aim of building ventilation is to create the indoor air quality more suitable for persons and processes than what naturally occurs in the unventilated building, and to reintroduce the positive effect of being exposed to the wind, to dilute and remove the pollutants that man himself, his activities, and the indoor surrounding produce.

Sustainable buildings design depends significantly on the used criteria for the indoor environment and building design as well as for operation. Indoor environment also affects health, productivity and comfort of the occupants. Recent studies have shown that cost of the deteriorated indoor environment for the society, employer and building owner are often higher than the cost of energy used in the same buildings. An energy declaration without a declaration related to the indoor environment makes no sense. There is therefore a need for specifying criteria for the indoor environment for design, energy calculations, performance and operation.

The additional objective of the last research work is perceived air quality. The interaction between building materials, structures, HVAC systems and occupancy performance is continously observed [3].

\section{Indoor environments}

Environmental quality of indoors is the conceptual system principle of architectural, constructional and environmental design development. Healthy/green/sustainable buildings are determined with mass and environs aspect. Mass aspect is determined by the system Building-Material-Subject and environs aspect is influenced by Building-Fluid-Subject system. Indoor environmental factors are determined by operative perceived comfort and hygiene criteria of indoor physical, chemical and biological compounds. The proper healthy/green/sustainable building design is doubtless task of mass and energy flow reduction. The mass flow reductions mostly consist in material recovery [4,5]. The problems with indoor air quality occur when energy flow reduction works together with changed material base composition and used services technology became dominant. There is no contradiction between indoor air quality and energy performance, but the more mass is changed the more energy flow is needed.

The investigation of selected chemicals (volatile organic compounds, particles, odors, formaldehyde, radon and nitrogen oxides) as well as were the main subjects of the last period interest $[1,6,7]$. The systematic indoor research studies in various types of buildings were carried out within the national research projects. On the base of the last large experimental monitoring results, it was possible to know the level of selected indoor chemicals occurrence, rank them as well as to predict the tendencies of occurrence and establish the priorities for the future (Table 1). 
Table 1. Indoor chemical pollutants occurrence ranking.

\begin{tabular}{|c|c|c|}
\hline Pollutants & Occurrence [\%] & Tendency \\
\hline VOCs & 85 & $\uparrow$ \\
\hline Odors & 78 & $\uparrow$ \\
\hline $\mathrm{PM}_{10}$ & 61 & $\uparrow$ \\
\hline Radon & 35 & $\downarrow$ \\
\hline $\mathrm{NO}_{2}$ & 19 & $\downarrow$ \\
\hline
\end{tabular}

It has become evident that variety building materials are the major source of indoor volatile organic compounds. The resulting interactions between indoor materials and indoor pollutants may significantly alter the concentrations of contaminants in indoor air. Interior surfaces are generally accepted as the main source of VOCs (Volatile Organic Compounds) emissions [1]. There has been growing evidence that building materials can affect the transport and exposure of indoor VOCs by sorption. The re-emission of adsorbed VOCs can dramatically elevate VOC concentrations in the indoor environment for months or years after a source event [1,2]. The surface sorption of materials emissions can reduce the concentration and improve the perceived air quality. Therefore, interaction between individual indoor materials (sorption ability of materials) is appropriate to study.

Presented results confirmed the highest priority of chemicals especially volatile organic compounds, odors, particles, radon and some oxidants. Indoor air quality become as integrating factor for perceived comfort and hygiene of indoors. Some interesting prodigies meet each other as environment, materials, constructions, HVAC systems, health, economy and productivity. The providing good indoor air quality can be achieved effectively by avoiding or reducing indoor air pollution sources and by selecting low-polluting building materials, both being low-cost and energy-efficient solutions.

Buildings may cause illness to their occupants, producing symptoms like irritation in the nose, throat, eyes, and skin, as well as shortness of breath, nausea, dizziness, and fatigue. These symptoms are commonly referred to as the Sick Building Syndrome (SBS). Such illness is usually minor and disappears when the sufferer leaves the building. Low rates of ventilation are often mentioned as a contributory factor. Allergy to indoor air contaminants is the main factor in sick building syndrome. These contaminants can be in the form of fine dust, fumes, fibers, odors or gases which are not removed by air conditioning filters or cleaning. Health effects from indoor air pollutants may be experienced soon after exposure or, possibly, years later. Immediate effects may show up after a single exposure or repeated exposures. These include irritation of the eyes, nose, and throat, headaches, dizziness, and fatigue. Such immediate effects are usually short-term and treatable. Sometimes the treatment is simply eliminating the person's exposure to the source of the pollution, if it can be identified. Symptoms of some diseases, including asthma, hypersensitivity pneumonitis, and humidifier fever, may also show up soon after exposure to some indoor air pollutants. The likelihood of immediate reactions to indoor air pollutants depends on several factors. Age and preexisting medical conditions are two important influences. In other cases, whether a person reacts to a pollutant depends on individual sensitivity, which varies tremendously from person to person. Some people can become sensitized to biological pollutants after repeated exposures, and it appears that some people can become sensitized to chemical pollutants as well. Another way to judge whether living environment has or could develop indoor air problems is to identify potential sources of indoor air pollution. Although the presence of such sources does not necessarily mean that person have an indoor air quality problem, being aware of the type and number of potential sources is an important step toward assessing the air quality in the indoor environment. 


\section{Buildings design}

When designing a building there are mainly four different factors to consider: regulations, customer requirements, knowledge and material information. These four factors have different goals, but one of them is to create a healthy buildings. Unfortunately there are also other goals that have to be fulfilled for each different factor, e.g. low cost, much space. The different goals are not always mutual for the different factors and that makes it sometimes hard to find good solutions for the indoor environment even when enough knowledge is available.

There can be little doubt that enormous progress has been made in improving the understanding of the design and construction practices that produce healthy buildings in terms of the impacts of buildings on occupant's health and well-being. A broader definition of healthy buildings included not only the impacts of buildings on their occupants but also on the larger environment. A healthy building is one that adversely affects neither the health of its occupants nor the larger environment.

The guidelines for healthy buildings project consists of design recommendations, design criteria and parameters, methods of suitable solution design and references to standard control. The building design should be based on a determination of what is important for environmental safety and established priorities for design efforts. The building design should include assessment of the amounts of surface area and mass of major building materials and products that will be used. The overview of the building use and the appropriate ventilation strategy as well as the detailed plan for the operation and maintenance of the building over its entire life cycle should be included in building design process. Analyzed specific features of buildings with sufficient indoor air quality to achieve required characteristic of healthy building, four main groups of tools do exist:

- Architectural and essential technical concept,

- Detailed architectural and construction design,

- Building environmental engineering,

- Operating and controlling systems.

The recognition of local and global environmental problems have stimulated considerable process which has been made during the past thirty years toward a more complete understanding of design and construction requirements for healthy buildings. The building design and construction toward sustainable practices were slowly shifted by awareness of environmental problems. Many environmental-friendly design and construction principles are widely accepted, but designers and constructors often fail to recommended practices or their clients fail to adopt state-of-the-art practices. Reasons for these failures include preference for and adherence to traditional practices, lack of expertise or short-term financial considerations. Meanwhile, awareness of environmental problems has produced an emerging shift toward purportedly green building practices that presume to include buildings that are healthy for their occupants.

\section{The differences between green and sustainable}

The idea of energy efficient, healthy buildings has been around for a long time, so why is it just now that the concept of green or sustainable building is entering the mainstream and catching the attention. There are probably several reasons; global warming, rising energy costs, the growing awareness and liability costs associated with sick building syndrome, declining oil reserves, and concerns about our limited water supply. The list goes on, but whatever the reason or reasons, sustainable building is a concept whose time has come. However, the words green and sustainable are often used interchangeably, and sustainable 
has a more precise meaning that is often obscured, distorted, and diluted by the commercialization and marketing of the green movement.

My personal definition of green is relatively simple. A building's design is green if its serves to reduce many of the harmful impacts buildings have on environment and building's inhabitants. So green building design revolves around four key issues:

- Designing for energy efficiency including the use of renewal energy sources,

- Creating a healthy indoor air environment with adequate ventilation,

- Making material choices that minimize volatile organic compounds,

- Specifying building materials and resources that are sustainable, have low embodied energy, and produce a minimal amount of upstream environmental impact.

Sustainability is ultimately a question of mass flows. Thus, the best way to make buildings more sustainable is to reduce mass flows. There are four main strategies for reducing mass flows in buildings:

- Re-use existing buildings,

- Re-use building materials,

- Recycle building materials that cannot be reused,

- Accommodate the same function in buildings.

In broadest sense, sustainability is an ethic which seeks to minimize the impact of human actions on the environment, and which strives to meet the needs of the present without compromising the ability of future generations to meet their own. Sustainable planning, design and development, then refers to strategies of practice and intervention aimed to accommodate present human needs in a manner which considers the full spectrum of natural and cultural system native to a site, and seeks a course of action minimally disruptive to those systems and which, ideally, results in their enhancement and long term viability. Sustainable design emphasizes relationships and processes rather than objects.

\section{Discussions}

While the designers maybe are motivated to create sustainable buildings, they are faced with number daunting challenges when they begin an actual project. First sustainable buildings have many definitions it is difficult to consistently identify what strategies should be included with sustainable project. A considerable part of this problem is that information is developing and changing rapidly. Second, there is an overwhelming amount of information on the subject that is either too time consuming to sift through or too fragmented to understand as a coherent whole. Third, while there already excellent sustainable building rating systems are available, they focus more on the strategies and less on the process required to make them work on an actual project.

There has been very limited attention to rigorous analysis of buildings actual environmental impacts to date. Healthy/green/sustainable building practices are typically applied in unsystematic and inconsistent ways often without resolution of inherent conflicts between and among such practices. Designers, products manufacturers, constructors, and owners declare their buildings and the applied technologies to be beneficial to the environment without validating these claims. Those seeking guidance to construct green buildings accept these claims without further analysis. This has resulted in the establishment and increasingly widespread acceptance of many practices that are of undetermined environmental impact. It has also produced a number of guidance documents that have begun to codify these practices. Much more work is required to determine the total environmental impacts of the buildings that are built. This work should include detailed evaluation of the pollution emissions, operation and use of buildings, and embodied and life cycle resource consumption. 
The design healthy/green/sustainable buildings should be based on a determination of what is important as well as on establishing of design efforts priorities. The design should include the identification of major materials and products that will be used, an overview of use of the building and the appropriate ventilation strategy and detailed plan for the operation and maintenance of the building over its entire life cycle.

Each strategy requires actions to be taken in some or of a building's life cycle, which is organized into these parts: planning, design, construction occupancy, and next use. The planning phase includes project initiation, programming and site selection. The schematic design, design development and construction documents are subparts of design process. The planning, design and construction parts represent building delivery process. The sustainable building guide must also include the entire occupancy period of the facility, particularly since public agency typically owns and operates these buildings. During occupancy many of the strategies must be implemented to be effective and the environmental impacts of operating and maintenance part of building life cycle offers critical opportunities to optimize the energy performance of a facility. At the end of the operating life of a building for a particular function, the next use of the facility will be analyzed and the process of planning, design construction and operation will begin once again.

\section{Conclusions}

The building design has to respect qualitative and quantitative requirements of indoor air quality parameters for environmental safety from space and time differences point of view. As the first stage of building design is the most important for final indoor air quality more and more by clear constructional architecture the benefit of environmental safety, good indoor air quality for health and productivity are dominant. The building design concerning to heath of occupants and hygienic performance regime can be realized only by interdisciplinary team of professionals respecting the healthy/green/sustainable building and indoor environment design.

Sustainable indoor environment design it is not easy task especially for designers. They do not practicing systematic attention to architectural, constructional and environmental attention together. Although they have some ethic motivation in using the newest indoor sciences knowledge, they meet a lot of problems in the real design process usually. A bulk of strategies do exist in addition they are permanently changed they are time-demanding and not quite understandable.

The author is grateful to national grant agency for supporting the indoor air sciences research project.

\section{References}

1. I. Senitkova, T. Tomcik, Advanced Science Letters, 19, 9 (2013)

2. I. Senitkova, M. Bucakova, Selected Scientific Papers, 3, 45-56 (2008)

3. I. Senitkova, Material Science Engineering C, 36, 6 (2014)

4. M. Culakova, I.Senitkova, A. Paulikova, Pollack Periodika, 7, 33-44 (2012)

5. I. Senitkova, P. Bednarova, JP Journal of Heat and Mass Transfer, 11, 29-42 (2015)

6. I. Senitkova, JP Journal of Heat and Mass Transfer, 12, 89-102 (2015)

7. I. Juhasova Senitkova, JP Journal of Heat and Mass Transfer, 13, 11 (2016) 